\title{
Recent advances in the diagnosis and management of pre-eclampsia
}

\author{
Kate E. Duhig and Andrew H. Shennan*
}

\author{
Address: Women's Health Academic Centre, King's College London, Westminster Bridge Road London, SE1 7EH, UK \\ * Corresponding author: Andrew H. Shennan (andrew.shennan@kcl.ac.uk) \\ Fl000Prime Reports 2015, 7:24 (doi:10.12703/P7-24) \\ All Fl000Prime Reports articles are distributed under the terms of the Creative Commons Attribution-Non Commercial License \\ (http://creativecommons.org/licenses/by-nc/3.0/legalcode), which permits non-commercial use, distribution, and reproduction in any medium, \\ provided the original work is properly cited. \\ The electronic version of this article is the complete one and can be found at: http://f1000.com/prime/reports/m/7/24
}

\begin{abstract}
Pre-eclampsia complicates around $5 \%$ of pregnancies and hypertensive disorders of pregnancy are responsible for over 60,000 maternal deaths worldwide annually. Pre-eclampsia is characterized by hypertension and features of multiple organ disease. Diagnosis remains a challenge as clinical presentation is highly variable and even with severe disease a woman can be asymptomatic. Pre-eclampsia is characterized by abnormal placentation with subsequent maternal inflammatory and vascular response. Improved understanding of the underlying pathophysiology relating to the role of angiogenic factors, has emerged and placed intense interest on their role in prognostic modelling or diagnosis of pre-eclampsia. This article summarizes new developments in diagnosis with a focus on angiogenic biomarkers for prediction of disease onset, and recent advances in management strategies for patients with pre-eclampsia.
\end{abstract}

\section{Introduction}

Pre-eclampsia complicates around 5\% of pregnancies and is a major cause of iatrogenic preterm birth. Hypertensive disorders of pregnancy are responsible for over 60,000 maternal deaths worldwide annually [1]. Both maternal and neonatal morbidity and mortality are increased in pregnancies complicated by pre-eclampsia, and there is significant personal cost to families affected by the disease and economic implications for the health service.

Diagnosing pre-eclampsia remains a challenge. It is characterized by hypertension and features of multiple organ disease. Clinical presentation is highly variable; and the disease often progresses over the course of weeks before diagnosis is confirmed. Women may present with mild late-onset hypertension, proteinuria, and a normally grown baby, which appear to have few long-term sequelae for mother or infant. Conversely, early-onset, severe maternal disease may be complicated by fetal intrauterine growth restriction; yet even with severe disease and grossly abnormal blood pressure and other test values, a woman can be asymptomatic. One group of authors reported that hypertension and proteinuria were absent in $38 \%$ of women who presented with an eclamptic fit [2], demonstrating that severe maternal adverse events occur without the traditional clinical definition of pre-eclampsia. One in twenty stillbirths without congenital abnormality are complicated by, or attributable to, pre-eclampsia [3] and may represent a cohort of women in whom fetal compromise is unrecognized. This article outlines recent developments in prediction, controlling blood pressure, and delivery, all of which are key to the management of pre-eclampsia.

\section{New developments in prediction}

A major goal toward improving antenatal management of pre-eclampsia is to develop accurate prediction models that identify women at high risk of disease. This would enable additional intensive monitoring of women throughout pregnancy and appropriate targeting of prophylaxis as well as earlier intervention. Not recognizing risk accounts for a considerable amount of substandard care in maternal deaths [4]. Early administration of antiplatelet agents (aspirin) prior to 16-weeks' gestation appears to reduce the risk of pre-eclampsia, with a particular reduction of the risk of preterm pre-eclampsia (that is, delivery before 37 weeks-relative risk

$0.11,95 \%$ confidence interval [CI] 0.04-0.33-[5] versus controls). However, secondary analysis of this nature may be prone to a number of biases. 
The pathophysiology of pre-eclampsia is not fully understood. Pre-eclampsia is a disorder characterized by abnormal placentation with subsequent maternal inflammatory and vascular response. Improved understanding of the underlying pathophysiology, particularly relating to the role of angiogenic factors, has emerged. It is established that, in normal pregnancies, trophoblasts help regulate spiral artery remodeling and enable normal vasculogenesis by releasing pro-angiogenic factors such as vascular endothelial growth factor (VEGF) and placental growth factor (PIGF) [6]. Soluble Fms-like tyrosine kinase 1 (sFlt-1) is a placentally derived variant of the VEGF receptor that is upregulated in pregnancies complicated by pre-eclampsia and has been shown to antagonize VEGF and PIGF, offsetting its pro-angiogenic actions [7]. In mouse models, genetic manipulation and expression of sFLT1 in murine placental tissue results in impaired vasculogenesis, an increase in systolic and diastolic blood pressure, proteinuria, and intrauterine growth restriction [8].

The developing understanding of pathophysiology has placed intense interest in the potential role of biomarkers in prognostic modeling. Significant differences were seen in the concentration of soluble endoglin (sEng) in pregnancies associated with pre-eclampsia versus controls at both 15 and 20 weeks' gestation [9]. In 2013, Myatt and colleagues [10] reported that, in a low-risk cohort of women, sFlt-1and PIGF increased from the first trimester throughout the second trimester of pregnancy in those remaining normotensive and that the rate of change of PIGF (but not sFlt-1) was significantly different in pregnancies that developed pre-eclampsia. Although firsttrimester prediction is not as impressive as in secondtrimester screening, evidence suggests that adding PlGF concentration at 14 to16-weeks' gestation to traditional clinical risk assessment did result in an increase in the identification of women at risk of preterm pre-eclampsia. In this study, the authors reported that the combination of change in angiogenic biomarkers between the first and second trimesters, with the addition of baseline clinical characteristics of race, body mass index, and blood pressure, increased predictive performance for severe and early-onset pre-eclampsia. Receiver operating characteristics curves for change from first to early second trimester in sEng, PIGF, and sFlt- 1 with the addition of clinical characteristics had areas under the curve of $0.88,0.84$, and 0.86 , respectively, and for early-onset pre-eclampsia with sensitivities of $88 \%$ (95\% CI 64-99), 77\% (95\% CI 50-93), and 77\% (95\% CI $50-93$ ) for $80 \%$ specificity. The authors believe that, even within a high-risk group, if the women can be risk-stratified to a normal risk of developing pre-eclampsia, their visiting schedules can be changed accordingly. In effect, the test supersedes the risk factor, so health economic benefit would be most valuable in a higher-risk group.
There is still interest in evaluating the potential use of a variety of biomarkers during the first trimester. Significant differences have also been demonstrated in firsttrimester mean levels of pregnancy-associated para protein A (PAPP-A), a disintegrin and metalloproteinase 12 (ADAM12) and PIGF [11], placental protein 13 [12], angiopoetin 1 and 2 [13], interleukin-1 beta and fibrinogen [14], and human chorionic gonadotropin (hCG) [15], but even as combinations their likelihood ratios (LRs) have been insufficient for use as reliable prognostic tools for pre-eclampsia.

Doppler velocimetry to assess impedance of uteroplacental flow in pregnancies complicated by pre-eclampsia was described in the 1980s $[16,17]$ and now forms part of second-trimester screening for women at high risk of developing pre-eclampsia. A review of over 20,000 women from 15 studies by Papageorghiou and colleagues [18] concluded that the LR for the subsequent development of pre-eclampsia in women with increased impedance to flow was about 6 but that for those with normal Doppler results the LR was about 0.5. Studies that assess the prediction of first-trimester ultrasound screening have shown that impedance to flow in the uterine arteries is increased in pregnancies that subsequently develop preeclampsia and fetal growth restriction [19]. The recent publication of a meta-analysis of Doppler ultrasound between $11+0$ and $14+0$ weeks' gestation demonstrated abnormal flow waveform for predicting early-onset preeclampsia with a sensitivity of $47.8 \%$ (95\% CI 39.0$56.8 \%$ ) and a specificity of $92.1 \%$ (95\% CI 88.6-94.6\%) [20]. For predicting pre-eclampsia at any gestation, the sensitivities were 26.4\% (95\% CI 22.5-30.8\%) and 93.4\% (95\% CI 90.4-95.5\%), respectively.

Although these first-trimester tests can risk-discriminate, they are far from perfect, even in combination. At present, there appears to be no method to accurately stratify healthy nulliparous women according to their risk profile for pre-eclampsia [21]. In practice, women with normal results will still need full antenatal care schedules to assess blood pressure and to exclude proteinuria and the development of pre-eclampsia as many women who present with pre-eclampsia are 'low risk' at booking. In addition, treatment is also inefficient, and women on treatment still require the same monitoring.

\section{Complexities of diagnosis}

There is a pressing need to develop methods for accurate diagnosis in women who present with suspected preeclampsia. This will include high- and low-risk women, whether on prophylaxis or not. This would enable clinicians to optimize surveillance intensity and target appropriate management in those with confirmed 
disease. It is these strategies that probably account for the success of antenatal care in reducing mortality in preeclampsia and explain the discrepancy between developed and other countries in the world. Rana and colleagues [22] summarized the challenges of prediction and diagnosis in a recent editorial. Hypertension is classified as a blood pressure of at least 140/90 mm Hg and is important in the diagnosis of pre-eclampsia. Blood pressure measurement is subject to considerable error; there is widely documented inter-observer error with poor correlation in the blood pressure readings taken by two observers in the same clinical setting [23]. Numerous studies detail the inaccuracies in equipment, particularly relating to oscillometric measurement of blood pressures in pregnant women in pre-eclampsia [24]. There is poor correlation between urinary dipstick testing and the quantification of proteinuria by using 24-hour urine collections [25]. Significant proteinuria is defined as greater than $300 \mathrm{mg}$ of protein in urine in 24 hours, but even this gold standard is prone to error [26]. There is considerable variability in the accuracy of protein/creatinine ratios when compared with 24-hour urine collections for the diagnosis of women with suspected disease [27]. Lindheimer and Kanter [28] discussed the complexities of assessing proteinuria in pregnancy and notably whether protein excretion remains constant over 24 hours, which may impact significantly on the reproducibility of the protein/ creatinine ratio at different time points. A recent study assessed serial protein creatinine ratio (PCR) measurements in a 24-hour period and showed that the PCRs correlated strongly with each other and with the 24-hour protein excretion but did show variation throughout the day [29]. Women with underlying renal disease with preexisting proteinuria, with or without hypertension, are at high risk of developing pre-eclampsia, yet diagnosis in this group is particularly challenging. Thresholds of blood pressure and proteinuria cannot be relied upon for discrimination of pre-eclampsia in this group, and clinicians must rely upon fetal parameters or the development of end-organ damage to confirm disease. Additional investigations may be necessary to risk-stratify in patients with renal disease, but none have proven to be specific. For all of these reasons, there has been an intense search for a specific marker of serious disease, and a role for angiogenic biomarkers such as PlGF as a novel diagnostic tool is emerging [22].

In 2012, Rana and colleagues [30] demonstrated that, in women presenting with suspected pre-eclampsia, the median sFlt-1/PlGF ratio at presentation was elevated in participants who experienced any adverse outcome compared with those who did not (47.0, 25-75th percentile 15.5-112.2 versus $10.8,25-75$ th percentile
4.1-28.6; $P<0.0001)$. In this prospective cohort of over 600 women, delivery occurred within 2 weeks of presentation in $86.0 \%$ of women with an sFlt-1/PlGF ratio of at least 85 compared with $15.8 \%$ of women with an sFlt-1/PlGF ratio of less than 85 (hazard ratio 15.2, 95\% CI 8.0-28.7).

In 2013, Chappell and colleagues [31] published a prospective multi-center study of women presenting with suspected pre-eclampsia to antenatal clinics or day assessment units. Maternal PlGF concentrations below the 5th centile were shown to have a high sensitivity (0.96, 95\% CI 0.89-0.99) and a negative predictive value (0.98, 95\% CI 0.93-0.995) for predicting the development of pre-eclampsia that requires delivery within 14 days (Figure 1).

In this study, of the 287 women recruited before 35 weeks' gestation, seven had a stillbirth. All of the pregnancies complicated by stillbirths occurred in the low-PlGF group ( $<5$ th centile), often weeks before the fetal death. This latter study used PIGF only, and the better results can be attributed to a more specific assay, which was provided by a different company and which also can be done rapidly at point of care.

PlGF concentrations were shown to have a greater area under the receiver operating curve $(0.87$; standard error 0.03 ) than all other commonly used tests in current clinical practice and any other study we are aware of $0.67(0.05)$ for systolic blood pressure, $0.66(0.05)$ for diastolic blood pressure, and 0.76 (0.04) for dipstick proteinuria.

The most likely area of clinical impact for PIGF is in 'point of care' testing in women posing a diagnostic challenge to the clinician. This testing should have a substantial impact on health resource use, avoiding unnecessary admissions for those who will have a more benign disease course and a longer 'time to delivery' interval, identified on the basis of a normal PIGF. Such a test has the potential to assist in risk stratification in women presenting with suspected pre-eclampsia, singling out those with low PIGF to receive intensive surveillance to avoid adverse outcomes such as fetal demise.

\section{Management \\ Blood pressure}

In women with fulminant disease, management includes antihypertensive drugs to optimize blood pressure control and allowing timely delivery of the baby. There is an increasing trend toward tighter blood pressure control in pre-eclampsia in those with essential or gestational hypertension. National Institute for Health 
Figure I. Time to delivery (median, interquartile range) stratified by PIGF concentration for all participants and for pre-eclampsia cases

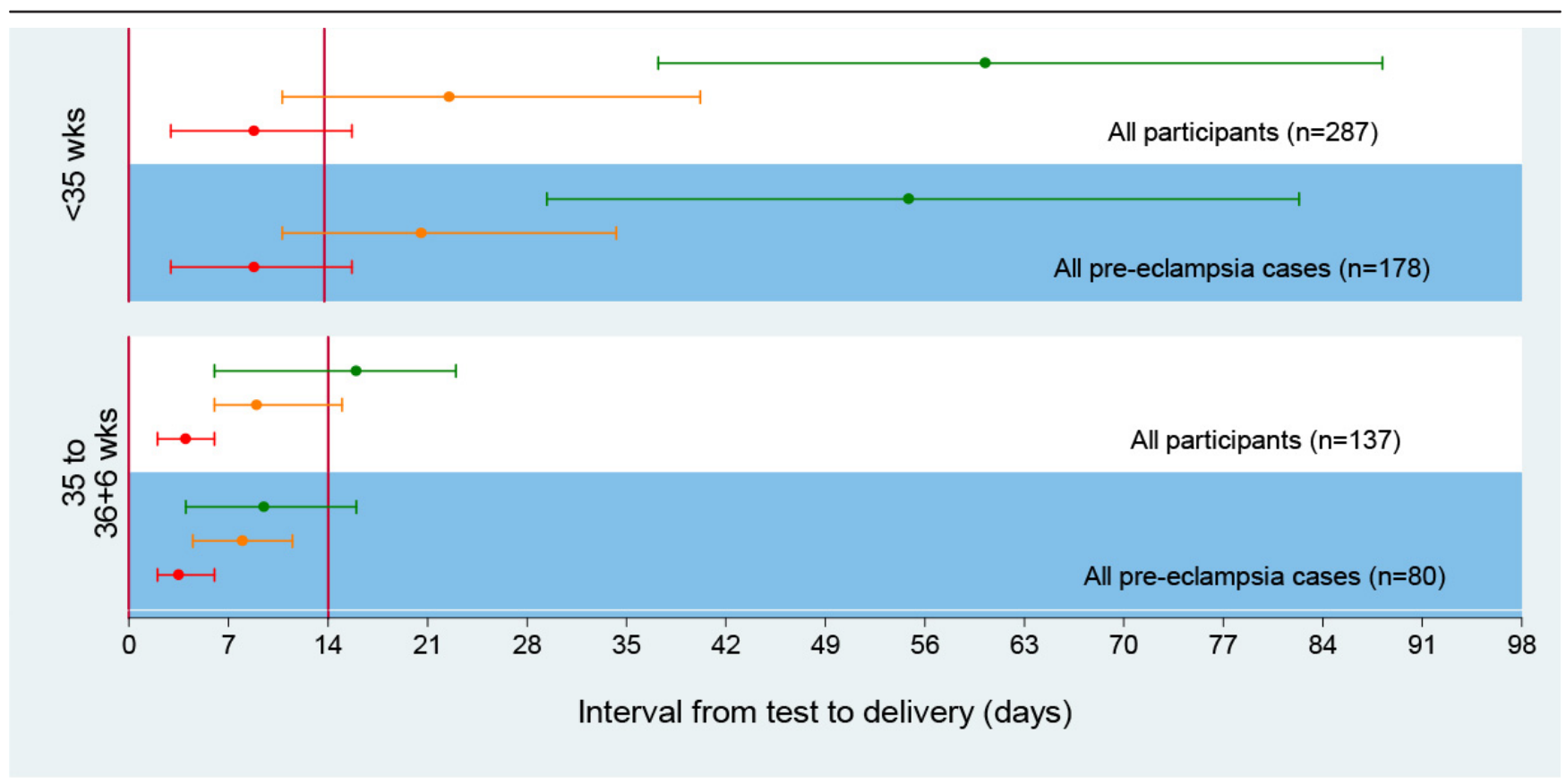

Red line indicates very low PIGF $(<12 \mathrm{pg} / \mathrm{mL})$; orange line, low PIGF ( $<5$ th centile); green line, normal PIGF $(\geq 5$ th centile). Abbreviations: IQR, interquartile range; PIGF, placental growth factor.

and Care Excellence (NICE) guidance now recommends keeping systolic blood pressure below $150 \mathrm{~mm} \mathrm{Hg}$ and diastolic blood pressure below 80-100 $\mathrm{mm} \mathrm{Hg} \mathrm{[32]} \mathrm{and}$ using labetolol as first-line treatment for hypertension over this threshold. There is general agreement that the judicious treatment of blood pressure is necessary to reduce morbidity, although the exact thresholds to treat do differ: the American College of Obstetricians and Gynecologists guidelines suggest treating blood pressure of more than $160 / 110 \mathrm{~mm} \mathrm{Hg}$, whereas the World Health Organization recommend treating systolic blood pressure over $170 \mathrm{~mm} \mathrm{Hg}$. The results of the impending Control of Hypertension In Pregnancy Study (CHIPS) trial (NCT01192412), with 'tight' (target diastolic blood pressure of $85 \mathrm{~mm} \mathrm{Hg}$ ) versus 'less tight' (target diastolic blood pressure of $100 \mathrm{~mm} \mathrm{Hg}$ ) control of hypertension in women with non-severe, non-proteinuric maternal hypertension at 14-33 weeks, are awaited. This may impact how clinicians manage women with essential or gestational hypertension.

\section{Magnesium sulphate}

Magnesium sulphate is recommended in severe preeclampsia to prevent eclamptic seizures in the mother [33]. This is established in clinical practice for women with severe hypertension or proteinuria or with mild to moderate hypertension or proteinuria with the addition of clinical or biochemical signs. A review by the Cochrane Collaboration from 2009 found that magnesium sulphate is also neuroprotective for the preterm infant ( $<37$ weeks) in preventing cerebral palsy (relative risk $0.68,95 \%$ CI 0.54-0.87) [34]. The number of women needed to be treated with magnesium sulphate to benefit one baby by avoiding cerebral palsy is 63 (95\% CI 43-155), and magnesium sulphate should now be part of established practice. There is a cohort of women with mild to moderate pre-eclampsia who do not meet maternal indications for magnesium sulphate but in whom, for fetal reasons, preterm delivery is necessary. It is appropriate now to give those women magnesium sulphate for fetal neuroprotection.

\section{Delivery}

Delivery recommendations from NICE [29] suggest conservative management below 34 weeks' gestation and urge that elective delivery before 34 weeks not be considered. The American College of Obstetricians and Gynecologists taskforce bulletin [35] states that, for women with mild gestational hypertension or preeclampsia without severe features, delivery at 37 weeks, rather than continued observation, is indicated. There is controversy but little evidence regarding the benefits of elective delivery between 34 and 37 weeks' gestation for those with mild or moderate hypertension, and NICE 
research recommendations highlight this as an important research question and call for randomized controlled trials. It remains unclear whether the risks of late preterm elective delivery for the baby outweigh the risks of severe disease and associated morbidity with conservative management.

\section{Conclusions}

Angiogenic markers, particularly PlGF, have considerable potential in the prediction and diagnosis of pre-eclampsia. They may also have use in triaging with preterm pre-eclampsia in terms of those patients in whom expectant management may be feasible. Until effective treatments are established, their biggest impact will remain in women presenting with suspected disease. Tighter control of blood pressure may impact on stroke risk and current substandard care associated with maternal death. Threshold for delivery has come down in recent years, and risk/benefit of earlier elective delivery is being investigated. Magnesium sulphate protects the preterm baby from neurological insults, and a low threshold for use in preterm pre-eclampsia is justified.

\section{Abbreviations}

CI, confidence interval; LR, likelihood ratio; NICE, National Institute for Health and Care Excellence; PCR, protein creatinine ratio; PlGF, placental growth factor; sEng, soluble endoglin; sFlt-1, soluble Fms-like tyrosine kinase 1; VEGF, vascular endothelial growth factor.

\section{Disclosures}

The authors declare that they have no disclosures.

\section{References}

I. The World Health Report 2005: Make every mother and child count. World Health Organization (WHO); 2005, [http://www.who. int/whr/2005/whr2005_en.pdf\#].

2. Douglas KA, Redman CW: Eclampsia in the United Kingdom. BMJ 1994, 309:1395-400.

\section{FlOOOPrime RECOMMENDED}

3. Perinatal Mortality 2008. Centre for Maternal and Child Enquiries. July 2010.

4. Shennan AH, Redman C, Cooper C, Milne F: Are most maternal deaths from pre-eclampsia avoidable? Lancet 2012, 379:1686-7.

5. Roberge $S$, Villa $P$, Nicolaides $K$, Giguère $Y$, Vainio $M$, Bakthi $A$, Ebrashy A, Bujold E: Early administration of low-dose aspirin for the prevention of preterm and term pre-eclampsia: a systematic review and meta-analysis. Fetal Diagn Ther 2012, 3I:|14|-6.

\section{RECOMMENDED}

6. Andraweera PH, Dekker GA, Roberts CT: The vascular endothelial growth factor family in adverse pregnancy outcomes. Hum Reprod Update 2012, 18:436-57.
7. Maynard SE, Min J, Merchan J, Lim K, Li J, Mondal S, Libermann TA, Morgan JP, Sellke FW, Stillman IE, Epstein FH, Sukhatme VP, Karumanchi SA: Excess placental soluble fms-like tyrosine kinase I (sFItI) may contribute to endothelial dysfunction, hypertension, and proteinuria in pre-eclampsia. J Clin Inves 2003, I I I:649-58.

FlOOOPrime

8. Kumasawa K, Ikawa M, Kidoya H, Hasuwa H, Saito-Fujita T, Morioka $Y$, Takakura N, Kimura T, Okabe M: Pravastatin induces placental growth factor (PGF) and ameliorates pre-eclampsia in a mouse model. Proc Natl Acad Sci USA 20I I, I 08: 1451-5.

FIOOOPrime RECOMMENDED

9. Myers JE, Kenny LC, McCowan LME, Chan EHY, Dekker GA, Poston L, Simpson, NAB, North RA: Angiogenic factors combined with clinical risk factors to predict preterm pre-eclampsia in nulliparous women: a predictive test accuracy study. BJOG 2013, 120:1215-23.

FlOOOPrime

RECOMMENDED

10. Myatt L, Clifton RG, Roberts JM, Spong CY, Wapner RJ, Thorp JM, Mercer BM, Peaceman AM, Ramin SM, Carpenter MW, Sciscione A, Tolosa JE, Saade G, Sorokin Y, Anderson GD: Can changes in angiogenic biomarkers between the first and second trimesters of pregnancy predict development of pre-eclampsia in a lowrisk nulliparous patient population? BJOG 20|3, I20:I I83-9|.

\section{FlOOOPrime}

RECOMMENDED

II. Odibo AO, Patel KR, Spitalnik A, Odibo L, Huettner P: Placental pathology, first-trimester biomarkers and adverse pregnancy outcomes. J Perinatol 2014, 34:186-9|.

12. Meiri H, Sammar M, Herzog A, Grimpel Y, Fihaman G, Cohen A, Kivity V, Sharabi-Nov A, Gonen R: Prediction of pre-eclampsia by placental protein 13 and background risk factors and its prevention by aspirin. J Perinat Med 2014.

13. Schneuer FJ, Roberts CL, Ashton AW, Guilbert C, Tasevski V, Morris JM, Nassar N: Angiopoietin I and 2 serum concentrations in first trimester of pregnancy as biomarkers of adverse pregnancy outcomes. Am J Obstet Gynecol 20I4, 2 I 0:345.e I-9.

14. Siljee JE, Wortelboer EJ, Koster, Maria PH, Imholz S, Rodenburg W, Visser, Gerard HA, Vries A de, Schielen, Peter CJI, Pennings, Jeroen LA: Identification of interleukin-I beta, but no other inflammatory proteins, as an early onset pre-eclampsia biomarker in first trimester serum by bead-based multiplexed immunoas-says. Prenat Diagn 2013, 33:1 I83-8.

15. Karahasanovic A, Sørensen S, Nilas L: First trimester pregnancyassociated plasma protein $A$ and human chorionic gonadotropin-beta in early and late pre-eclampsia. Clin Chem Lab Med 2014, 52:52I-5.

16. Campbell S, Diaz-Recasens J, Griffin DR, Cohen-Overbeek TE, Pearce JM, Willson K, Teague MJ: New doppler technique for assessing uteroplacental blood flow. Lancet 1983, I:675-7.

17. Ducey J, Schulman H, Farmakides G, Rochelson B, Bracero L, Fleischer A, Guzman E, Winter D, Penny B: A classification of hypertension in pregnancy based on Doppler velocimetry. Am J Obstet Gynecol 1987, 157:680-5.

18. Papageorghiou AT, Yu, Christina KH, Nicolaides KH: The role of uterine artery Doppler in predicting adverse pregnancy outcome. Best Pract Res Clin Obstet Gynaecol 2004, 18:383-96.

19. Harrington K, Goldfrad C, Carpenter RG, Campbell S: Transvaginal uterine and umbilical artery Doppler examination of I 2-16 weeks and the subsequent development of preeclampsia and intrauterine growth retardation. Ultrasound Obstet Gynecol 1997, 9:94-100.

20. Velauthar L, Plana MN, Kalidindi M, Zamora J, Thilaganathan B, Illanes SE, Khan KS, Aquilina J, Thangaratinam S: First-trimester uterine artery Doppler and adverse pregnancy outcome: a meta-analysis involving $\mathbf{5 5 , 9 7 4}$ women. Ultrasound Obstet Gynecol 20I4, 43:500-7. 
21. North RA, McCowan, Lesley ME, Dekker GA, Poston L, Chan, Eliza HY, Stewart AW, Black MA, Taylor RS, Walker JJ, Baker PN, Kenny LC: Clinical risk prediction for pre-eclampsia in nulliparous women: development of model in international prospective cohort. BMJ 20II, 342:d1875.

22. Rana S, Karumanchi SA, Lindheimer MD: Angiogenic factors in diagnosis, management, and research in pre-eclampsia. Hypertension 2014, 63:198-202.

\section{FlOOOPrime}

\section{RECOMMENDED}

23. Villar J, Repke J, Markush L, Calvert W, Rhoads G: The measuring of blood pressure during pregnancy. Am J Obstet Gynecol I989, 161:1019-24.

24. Villar J, Say L, Shennan A, Lindheimer M, Duley L, Conde-Agudelo A, Merialdi M: Methodological and technical issues related to the diagnosis, screening, prevention, and treatment of preeclampsia and eclampsia. Int J Gynaecol Obstet 2004, 85(Suppl I): S28-4I.

25. Durnwald C, Mercer B: A prospective comparison of total protein/creatinine ratio versus 24-hour urine protein in women with suspected pre-eclampsia. Am J Obstet Gynecol 2003, I89:848-52.

26. Waugh J, Bell SC, Kilby MD, Lambert P, Shennan A, Halligan A: Urine protein estimation in hypertensive pregnancy: which thresholds and laboratory assay best predict clinical outcome? Hypertens Pregnancy 2005, 24:29I-302.

27. Morris RK, Riley RD, Doug M, Deeks Jl, Kilby MD: Diagnostic accuracy of spot urinary protein and albumin to creatinine ratios for detection of significant proteinuria or adverse pregnancy outcome in patients with suspected pre-eclampsia: systematic review and meta-analysis. BMJ 20I2, 345:e4342.

\section{FlOOOPrime}

28. Lindheimer MD, Kanter D: Interpreting abnormal proteinuria in pregnancy: the need for a more pathophysiological approach. Obstet Gynecol 2010, I I 5:365-75.

FlOOOPrime
29. Verdonk K, Niemeijer I, Hop W, Rijke Y de, Steegers E, van den Meiracker, Ah, Visser W: Variation of urinary protein to creatinine ratio during the day in women with suspected pre-eclampsia. BJOG 2014, I 2 I:|660-5.

\section{FlOOOPrime

RECOMMENDED

30. Rana S, Powe CE, Salahuddin S, Verlohren S, Perschel FH, Levine RJ, Lim K, Wenger JB, Thadhani R, Karumanchi SA: Angiogenic factors and the risk of adverse outcomes in women with suspected pre-eclampsia. Circulation 2012, I 25:91 I-9.

\section{FlOOOPrime}

\section{RECOMMENDED}

31. Chappell LC, Duckworth S, Seed PT, Griffin M, Myers J, Mackillop L, Simpson N, Waugh J, Anumba D, Kenny LC, Redman, Christopher W G, Shennan AH: Diagnostic accuracy of placental growth factor in women with suspected pre-eclampsia: a prospective multicenter study. Circulation 2013, I28:2 |2|-3|.

32. CGI07 Hypertension in pregnancy: NICE guideline, 2012.

33. Altman D, Carroli G, Duley L, Farrell B, Moodley J, Neilson J, Smith D: Do women with pre-eclampsia, and their babies, benefit from magnesium sulphate? The Magpie Trial: a randomised placebo-controlled trial. Lancet 2002, 359:1877-90.

\section{FlOOOPrime}

\section{RECOMMENDED}

34. Doyle LW, Crowther CA, Middleton P, Marret S, Rouse D: Magnesium sulphate for women at risk of preterm birth for neuroprotection of the fetus. Cochrane Database Syst Rev 2009: CD00466I

\section{FlOOOPrime}

RECOMMENDED

35. American College of Obstetricians and Gynecologists, Task Force on Hypertension in Pregnancy: Hypertension in pregnancy. Report of the American College of Obstetricians and Gynecologists' Task Force on Hypertension in Pregnancy. Obstet Gynecol 2013, | 22: | |22-3|

FlOOOPrime

